\title{
Neuropsychological correlates of a right unilateral lacunar thalamic infarction
}

\author{
Y D Van Der Werf, J G E Weerts, J Jolles, M P Witter, J Lindeboom, Ph Scheltens
}

Department of Anatomy and Embryology Y D Van Der Werf M P Witter

Department of Radiology J G E Weerts

Department of Medical Psychology $\mathrm{J}$ Lindeboom

Department of Neurology, Graduate School for

Neurosciences

Amsterdam, Research Institute

Neurosciences Vrije

Universiteit

Amsterdam, The

Netherlands

$\mathrm{Ph}$ Scheltens

Department of

Biological Psychology,

The Maastricht Brain and Behaviour

Institute, Maastricht, The Netherlands

J Jolles

Correspondence to: Dr Y D Van Der Werf, Department of Anatomy and Embryology, Graduate School for Neurosciences Amsterdam, Research Institute Neurosciences Vrije Universiteit Amsterdam, The Netherlands

Received 16 December 1997 and in revised form

1 June 1998

Accepted 29 June 1998

\begin{abstract}
Objectives-To report on a patient with a lacunar infarction in the right intralaminar nuclei of the thalamus. The role of the thalamic intralaminar nuclei in cognitive function is as yet insufficiently known. The patient described has shown signs of apathy and loss of initiative, in combination with cognitive deficits, which have persisted essentially unaltered up to the present day since an abrupt onset 17 years ago.
\end{abstract}

Methods-High resolution MRI was performed to show the extent of the lesion; a combination of published and experimental neuropsychological techniques was administered to show the nature of the cognitive defects; Single photon emission computed tomography (SPECT) was employed to obtain a measure of cortical perfusion.

Results-Brain MRI disclosed an isolated lacunar infarction in the dorsal caudal intralaminar nuclei of the thalamus. Neuropsychological evaluation indicated problems with attention and concentration, executive disturbances, and memory deficits both in the visual and verbal domains. The memory deficits could not be attributed to problems in the early stages of information processing, and are hence regarded as resulting from a failure of retrieval rather than encoding or storage. Brain SPECT disclosed a hypoperfusion of the right frontal cortex.

Conclusion-The data indicate that the cognitive profile is the result of a dysfunction of executive functions. This is corroborated by the finding of decreased blood flow in the right frontal cortex, and by evidence from the neuroanatomical literature. Thus the dysexecutive symptoms are thought to be caused by disconnection of the prefrontal cortex from the brainstem activating nuclei through the strategic localisation of the right thalamic infarction.

(f Neurol Neurosurg Psychiatry 1999;66:36-42)

Keywords: amnesia; dysexecutive; neuropsychology; diencephalon

Thalamic infarctions have long been noted to cause memory deficits reminiscent of those found after lesions of the medial temporal lobe or hippocampal formation. ${ }^{1-3}$ In addition, symptoms of a more frontal type have been reported after thalamic infarction. ${ }^{45}$ These comprise a constellation of symptoms charac- terised as dysexecutive problems. Often both memory and executive dysfunctions occur simultaneously after thalamic infarctions, ${ }^{6}$ but in some patients either pure amnesia or executive dysfunction may be seen. ${ }^{7}$ The amnesic and dysexecutive effects are most pronounced in bilateral and left unilateral infarctions; the role of the right thalamus is less clear. ${ }^{8}$

It is insufficiently known which structures in the thalamus mediate the cognitive dysfunctions in these patients, because the infarctions in the thalamus which give rise to cognitive disturbances are relatively large and usually encompass several nuclei. This has hampered understanding the role of individual nuclei and has given rise to an ongoing debate on the involvement of thalamic structures in cognitive functioning. ${ }^{8}{ }^{9}$ In this case study we report the profile of cognitive disturbances seen after a right unilateral lacunar infarction in the thalamic region, so small as to be contained within the dorsal caudal internal medullary lamina.

\section{Methods}

CLINICAL METHODOLOGY

Routine neurological and laboratory examination were carried out. As gross measures of cognitive status, the mini mental state examination $^{10}$ and the cognitive screening test (a Dutch modification of the short portable mental status questionnaire ${ }^{11}$ ) were administered. This test has been shown to be sensitive to cognitive decline as seen in demented patients.

NEUROPSYCHOLOGICAL METHODOLOGY

Informed consent according to the declaration of Helsinki was obtained.

Our patient has been tested repeatedly in the course of the past 17 years, with consistent results. Because of this, only the data obtained during the most recent neuropsychological investigations (1997) will be discussed. Published and local normative data are used for comparisons. Many of the disturbances shown by this patient are in the realm of behavioural deficiencies, which cannot be adequately described by neuropsychological measures. A substantial part of the clinical outcome is therefore presented in the results section in descriptive terms.

Verbal abilities were tested with the Dutch version of the Aachen aphasia test (AAT). ${ }^{12}$ Hand preference was assessed by means of a questionnaire ${ }^{13}$ containing 16 items of everyday activities such as using a pair of scissors, throwing a ball, and hammering a nail.

Intellectual functioning was assessed with the three subtest version of the Groninger intelligence test (GIT), a reliable indicator of 
the full scale IQ. ${ }^{14}$ The premorbid IQ was also estimated on the basis of socioeconomical background and education. ${ }^{15}$

Memory performance was assessed using immediate and delayed recall of a Dutch verbal learning test, ${ }^{16}{ }^{17}$ a modification of the Rey auditory verbal learning ${ }^{18}$; copying, direct, and delayed recall of the Rey-Osterrieth complex figure with recognition trial ${ }^{19}$; the visual association learning task, ${ }^{20}{ }^{21}$ designed to circumvent laborious and effortful encoding by presenting associated objects and subsequently asking the patient to recall the object missing when shown the incomplete figures. It is assumed that this task is sensitive to early manifestations of anterograde amnesia in patients with Alzheimer's disease by tapping automatic encoding; the recognition memory test for faces $^{23}$; digit span forward and backward, using three sequences per sequence length ${ }^{18}{ }^{24}$; and the Brown-Peterson paradigm. The last was performed as described in Lezak, ${ }^{18}$ with intervals of $0,3,9$, and 18 seconds, each administered 10 times except for the 0 second interval, which was administered five times. With the exception of the 0 second interval, the patient was asked to count backwards from a given number for the duration of the interval.

The range of memory tests used permits an overview of the performance of the patient in the various memory modalities currently recognised: immediate memory is assessed with the digit span and Brown Peterson paradigm; short term memory in the auditory domain is measured with the verbal learning test, in the visual domain with the recognition memory test and the Rey-Osterrieth complex figure test; long term memory is probed similarly with the delayed recall trials of the verbal learning test and the Rey-Osterrieth complex figure test. In addition, a differentiation can be made in the process of memory formation by the use of measures sensitive to either encoding (visual association learning test) or retrieval (recognition of the verbal learning test and the Rey-Osterrieth complex figure test).

The tasks measuring executive functioning administered here, consist of a rather heterogeneous constellation of tests, shown to be sensitive for dysfunction of the frontal lobes. The tests administered are the Dutch version of the Stroop test (modified after Stroop ${ }^{25}$ ), trailmaking $\mathrm{A}$ and $\mathrm{B},{ }^{18}$ word fluency for animals and professions (norms from Luteijn and Van der Ploeg ${ }^{15}$ ), the Wisconsin test, ${ }^{26}$ and the Tower of London test (modified after Shallice ${ }^{27}$ ). This array of tests was chosen to assess the different functions ascribed to the intact prefrontal cortex-namely, inhibition of a prepotent response, or shifting abilities (Stroop and trailmaking tests, Wisconsin card sorting); semantic organisation (category fluency); and planning of a sequence of steps (Tower of London test).

NEUROIMAGING METHODOLOGY

Brain CT was performed in 1983, three years after surgery. Brain MRI at 1.5 Tesla involving $\mathrm{T} 1$ weighted and $\mathrm{T} 2$ weighted axial, coronal, and parasagittal slices and PET using ${ }^{99} \mathrm{TcHM}-$
PAO were performed 16 years after onset of the symptoms. Electroencephalographic recordings were made both in 1983 and 1994 .

\section{Results}

CASE REPORT

In 1980 our patient, a 44 year old white man, was referred to a general hospital for routine surgery involving lumbar disk herniation. The procedure was uneventful and no postoperative complications occurred. His wife, however, immediately noted behavioural changes postoperatively. At the time of surgery, he owned a flourishing company selling flower bulbs, and occupied many board positions in his field of work, but was unable to keep up these activities after the operation. He is currently doing odd jobs at his company which is now run by his wife. He is still a hard worker, and when left to do simple straightforward labour, he will carry on for 11 hours at a stretch without complaints of fatigue or boredom and without pausing to eat or drink. His wife describes this and other behaviours as inflexible. When asked to perform a certain task - for example, washing up, he will carry it out being perfectly able to focus on it, but is unable to cope with interventions. $\mathrm{He}$ will only perform labour when explicitly asked to do so. When left to himself, he will tend not to initiate any activity. Having been a lively and creative character, involved in sports and described as a great family man, he had become apathetic and lethargic. His wife describes how he can be found sitting in his bedroom on his own, when his family is downstairs on social evenings. This behaviour seems not to arise from discontent or anger, but from disinterest. He shows a remarkable lack of facial and verbal expressiveness and initiative, but is perfectly compliant. He has lost sexual interest, and often falls asleep when watching television. He complains of a short span of attention and he no longer reads, because "it takes him too long to finish", he forgets errands and he sometimes loses the gist of what he was saying.

In addition, he and his family complain of deficient memory. Indeed, though he has met his consulting neurologist (PS) and neuropsychologists (JL and YDvdW) often over the past few years, he fails to remember their names despite recognising their faces. By contrast, his memory for the past seems well preserved and he is still valued for his expert knowledge concerning taxonomy and maintenance of flower bulbs. During the the past 17 years, his condition has changed little.

\section{CLINICAL RESULTS}

Neurological examination and routine laboratory testing disclosed no abnormalities, although speech was slightly hypophonic. Tendon reflexes were brisk, both plantar reflexes being flexor. Extrapyramidal signs were absent. Tactile perception of objects with the dominant and non-dominant hand was undisturbed and by contrast with most tests, performed quickly.

The mini mental state examination score was 25 out of 30 . Although impaired, the score was above the cut off for dementia. ${ }^{18}$ Items missed 
Table 1 Memory tests

\begin{tabular}{llll}
\hline Test & Measure & Raw scores & Statistics \\
\hline Verbal learning test & 5 trials: & No of words per trial: $2,3,5,4,9$ & $10^{\text {th }}$ percentile \\
& Delay $(1 \mathrm{~h}):$ & No of words: 4 & $50^{\text {th }}<$ percentile $<70^{\text {th }}$ \\
Recognition: & No of words: $24 / 30$ & $1^{\text {st }}$ percentile \\
Rey complex figure & Copy: & No of correct elements: $27 / 36$ & $1^{\text {st }}$ percentile \\
& Delay (3'): & No of correct elements: $11,5 / 36$ & $14^{\text {th }}$ percentile \\
& Delay (30'): & No of correct elements: $12,5 / 36$ & $18^{\text {th }}$ percentile \\
VALT & Recognition: & No of correct elements: $16 / 24$ & $1^{\text {st }}$ percentile \\
& Two trials: & No of correct associations: $11 / 12,12 / 12$ & $70^{\text {th }}$ percentile \\
RMT-faces & Delay (30'): & No of correct associations: $12 / 12$ & $100^{\text {th }}$ percentile \\
Digit span & Recognition & No of correct faces: $25 / 50$ & $1^{\text {st }}$ percentile \\
& Forward: & Span length: 6 & $42^{\text {nd }}$ Percentile \\
Brown-Peterson: & Backward: & Span length: 3 & $25^{\text {th }}$ Percentile \\
& 0 s interval: & No correct: $5 / 5$ & \\
& $3 \mathrm{~s}:$ & No correct: $0 / 10$ & \\
& $9 \mathrm{~s}:$ & No correct: $0 / 10$ & \\
\hline
\end{tabular}

VALT $=$ Visual association learning task; $R M T=$ recognition memory test.

were the recall of three words, repetition, and one item of orientation. On the cognitive screening test, our patient obtained a near perfect score of 19 (max 20 ) which is not indicative of cognitive decline.

NEUROPSYCHOLOGICAL RESULTS

The AAT excluded the presence of aphasia with a certainty of $70.3 \%$. Speech was slightly slow: verbal output in response to standardised questions in the AAT was measured to be 91 words/minute, placing our patient in the low normal range. ${ }^{12}$ On the hand preference questionnaire a maximum of 10 was obtained, a score shared by $89.4 \%$ of right handed controls and considered to indicate "extreme right handedness" ${ }^{13}$; scores of $\geqslant 8$ are reached by $98.3 \%$ of right handed controls. Simple motor reaction times to auditory and visual stimuli using either the dominant or the non-dominant hand were not significantly different from those obtained by healthy control subjects.

The three subtest version of the Groninger intelligence test (GIT) indicated an IQ of 58. However, socioeconomical background and education (10 years of formal education) indicated a score between 100 and 105 .

Recall of 15 unrelated words disclosed an immediate recall score falling below the $10^{\text {th }}$ percentile of scores obtained by controls; retention of stimulus words after 30 minutes was at the level expected on the basis of the immediate recall, indicating a normal rate of forgetting. His recognition score, although defective compared with age matched healthy controls, nevertheless showed that a significant proportion of the words could still be recog-

Table 2 Executive tasks

\begin{tabular}{llll}
\hline Test & Measure & Raw scores & Statistics \\
\hline Stroop test (100 items/condition) & I: Colour reading & Duration: $60 \mathrm{~s}$ & $<10^{\text {th }}$ percentile \\
& II: Colour naming & $\begin{array}{l}\text { Duration: } 113 \mathrm{~s} \\
\text { Duration: } 347 \mathrm{~s} \text {, errors: } 20 \text { uncorrected, } 1\end{array}$ & $<10^{\text {th }}$ percentile \\
& III: Colour/word & corrected & $50^{\text {phcentile }}$ \\
Trailmaking & A: & Duration: $49 \mathrm{~s}$ & $50^{\text {th }}$ percentile \\
& B: & Discontinued after $333 \mathrm{~s}$ & $<10^{\text {th }}$ percentile \\
$t=36$ & $t=28$ \\
Fluency & No of animals $(60 \mathrm{~s})$ & 11 & \\
& No of professions & 6 & \\
(60 s) & No of categories & $0 / 6$ & \\
WCST & 2,3 , and 4 step trials & No of errors & \\
Tower of London & 5,6 , and 7 step trials & From 2 to 12 steps over criterion & \\
\end{tabular}

WCST: Wisconsin card sorting test nised. Likewise, in the visual association learning task, an unintentional memory task employing automatic encoding ${ }^{20}$ no evidence of anterograde amnesia was obtained. In the first trial 11 of the total of 12 associations were recalled (cumulative percentage 70 for a group of neurological patients), in the second all 12 could be reproduced (cumulative percentage 100). After an interval of 30 minutes, the 12 recognition memory test for faces rendered a score at chance level. Copy of the Rey figure was defective ( $1^{\text {st }}$ percentile) as was recall, both after 3 and 30 minutes $\left(14^{\text {th }}\right.$ and $18^{\text {th }}$ percentiles, respectively); the recognition score fell in the first percentile. The patient obtained a digit span forward of 6 ( $42^{\text {nd }}$ percentile), and a digit span backward of 3; the backward digit span is scored relatively to the forward score, falling in the 25th percentile. In the Brown-Peterson paradigm, none of the stimuli could be recalled faultlessly after the counting procedure. In the latter test, the patient showed perseverative tendencies in his answers.

The error pattern of the recognition measures indicated a preponderance of false negative errors over false positives (verbal learning test recognition trial $5 v 1$; Rey recognition $5 v$ 2) (table 1).

Conspicuously low scores on tasks measuring frontal and executive capacities were consistently obtained; the interference condition of the Stroop test could not be performed adequately due to an inability to repress reading out the printed words; although performance on the conditions I and II (reading and naming of colours respectively) were already slow, the additional slowness in associations could still be produced. The 

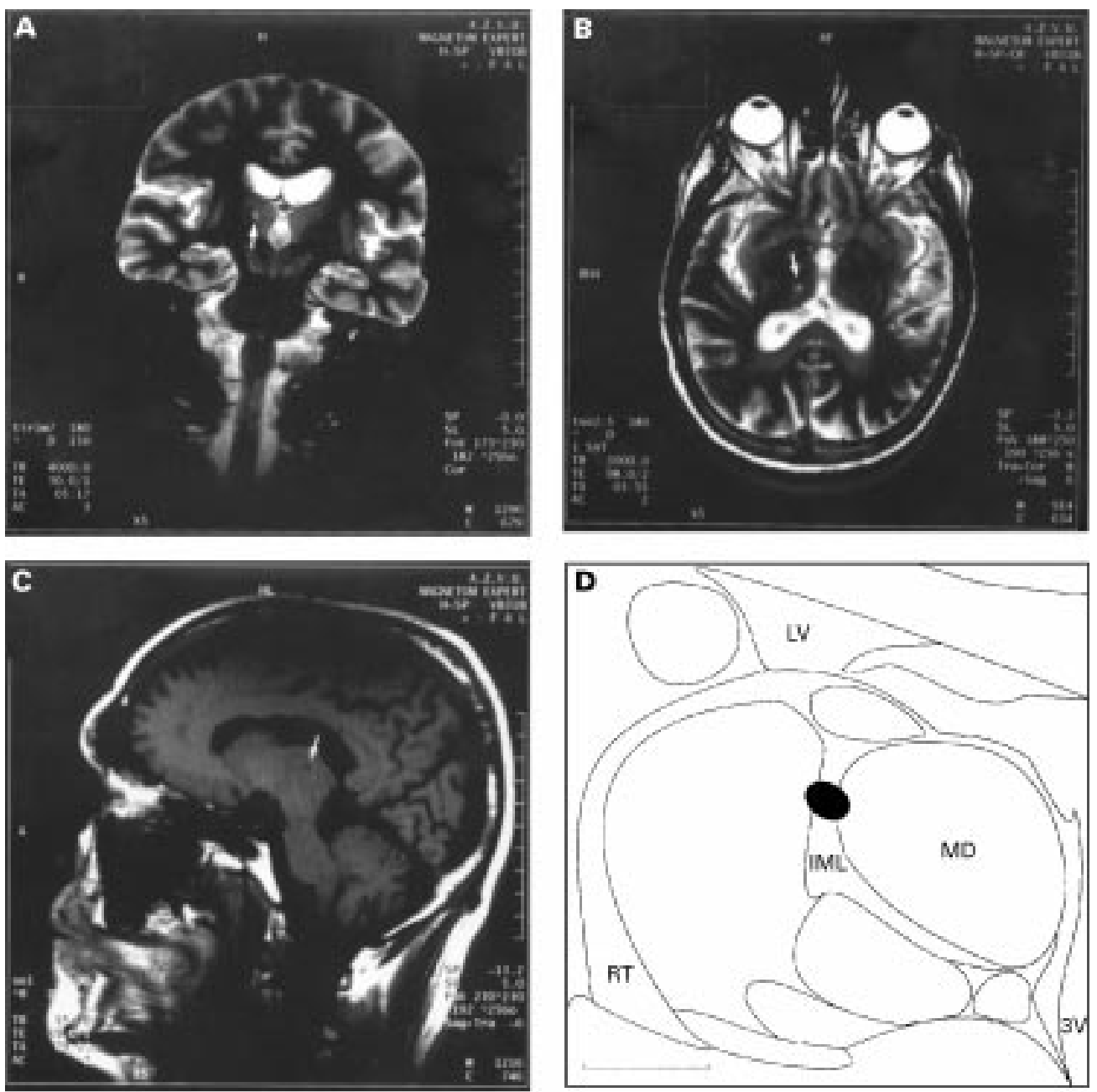

Brain MRI showing the site of the right sided lacunar infarction (arrows) in the thalamus in T2 weighted coronal and axial sections, and $T 1$ weighted parasagittal sections ( $A, B$, and $C$, respectively). (D) shows a reconstruction of the lesion in an adapted drawing from a stereotaxic atlas of the human brain. ${ }^{29}$ The lesion is indicated by the black dot. Scale bar= 5 mm. $M D=$ mediodorsal nucleus, $I M L=$ internal medullary lamina (intralaminar nuclei), LV=lateral ventricle, $R T=$ reticular nucleus, $3 V=$ third ventricle. In $(A),(B)$, and $(D)$ the right side is shown on the left.

the interference condition was disproportional. Trail making part B was not completed because of an inability to grasp the principle of alternating letters and digits; scores on fluency measures fell between 1 SD and 3 SD short of the mean; on the classic frontal task, the Wisconsin card sorting test, the patient was unable to sort according to colour and therefore did not achieve a single category. On the Tower of London test, all trials were completed but the more complicated sequences only after trial and error placements, sometimes leading to sequences of 17 steps in trials with a minimum sequence length of five steps.

All tasks were performed at extremely low speed and instructions had to be repeated several times (table 2).

NEUROIMAGING RESULTS

Brain CT and radiography of the skull disclosed no abnormalities. Brain MRI showed some cortical and hippocampal gyral widening and a small lesion in the right thalamus. With the aid of stereotaxic atlases of the human thalamus, ${ }^{28}{ }^{29}$ this lesion was judged by us, together with a team of neuroanatomical experts (see acknowledgements), to lie in the region of the dorsal caudal intralaminar nuclei (figure). The intralaminar nuclei are divided into a rostral group (centromedial, paracentral, central lateral, and rhomboid nuclei) and a caudal group (centre médian and parafascicular nuclei). The densest projections of the caudal intralaminar nuclei seem to involve the striatum, but there are also widespread projections to the cerebral cortex, most notably the frontal and parietal areas. ${ }^{30}$ Based on the appearance of the lesion on the $\mathrm{T} 1$ and $\mathrm{T} 2$ weighted sequences, it was judged to be a lacunar infarct. Tentatively, the infarct arose during surgery, possibly from hypoperfusion of the small vessels of the deep diencephalic structures, or from an embolism.

Brain SPECT disclosed a moderate hypoperfusion of the right frontal cortex, and EEG recordings showed diffuse slowness in the cortical and subcortical regions.

\section{Discussion}

CLINICAL, NEUROPSYCHOLOGICAL, AND

NEUROIMAGING DATA

In this report, we describe a patient with a thalamic lesion in the region of the right intralaminar nuclei, resulting in a conspicuous 
slowness, inflexibility, and lack of concentration. These effects are apparent both in the behavioural and cognitive domain. The second can be judged from, for example, the BrownPeterson paradigm, Stroop test, and trailmaking test. In addition, there is ample evidence of decreased conceptual capacities and abilities to look ahead as seen in the classic tests for frontal symptoms, the Wisconsin card sorting test, and Tower of London test. Also, the patient shows an anterograde memory deficit when asked to free recall words, recognise faces, or draw a figure from memory. By contrast with the apparent anterograde amnesia on these tasks, however, the visual association learning task is performed at a normal level, with good retention after an interval of 30 minutes. This shows that automatic encoding is still functioning, which is contrary to the encoding deficits found in patients with a true anterograde amnesia resulting from a formal amnesic syndrome. ${ }^{31}$ Functional imaging data from our laboratory, using the visual association paradigm, show selective activation of the hippocampal formation. ${ }^{21}$ We therefore assume the cognitive operations involving the hippocampus in this patient to be intact.

Also, recall of the Rey figure did not deteriorate between immediate and delayed recall sessions and the recognition score on the verbal learning test was markedly better than would be expected from the delayed recall score. These results indicate a normal rate of forgetting, again unlike the anterograde amnesia seen in the amnesic syndrome after hippocampal or anteromedial thalamic damage..$^{1-2} 8{ }^{32-34}$ On the basis of these considerations, it can be argued that the patients' complaints of memory deficits and the deficient results on formal memory tests described herein, are secondary to a disruption of the use of mnemonic strategies and planning abilities. This disruption is thought to result from a dysfunction of the prefrontal lobes, in turn induced by the loss of activating intralaminar thalamic input.

It is important to note that although the test scores of our patient are almost invariably low, a clinical diagnosis of dementia cannot be made. Firstly, the pattern of neuropsychological deficits arose suddenly and has remained stable over the past 17 years. This excludes the possibility of a slowly progressive neurodegenerative dementing disorder. Secondly, the mini mental state examination and a Dutch test for orientation, personal, and general knowledge (cognitive screening test) showed no evidence of cognitive deterioration. Thirdly, administration of a test for automatic encoding (visual association learning test) which has been shown to be dependent on functioning of the hippocampal and parahippocampal cortices, ${ }^{21}{ }^{35}$ failed to show an anterograde memory deficit. Lastly, the normal rate of forgetting and the superiority of recognition over recall measures, as stated in the above paragraph, argue against an anterograde amnesia which is the hallmark of dementia.

Thus the clinical impression and the profile of test scores combined with the ipsilateral frontotemporal hypoperfusion on SPECT indi- cate a dysfunction of executive functions underlying the memory deficits.

COMPARISON WITH THE LITERATURE ON THALAMIC INFARCTIONS.

Our results agree with those obtained by Mennemeier et $a l^{36}$ describing a patient with a selective lesion in the left intralaminar nuclei. The verbal amnesic symptoms shown by this patient were due to a lack of concentration rather than a deficit in the early stages of memory formation. When she was allowed to use strategies for encoding, her scores reached normal levels. Mennemeier et al conclude that the caudal intralaminar nuclei are not memory structures themselves, but exert indirect influence on memory through the regulation of attention for simultaneous activities. In a follow up paper, Mennemeier et $a^{\beta^{7}}$ speculated that the motor deficits in this patient can be attributed to a deafferentiation of the basal ganglia caused by the intralaminar lesion, whereas the cognitive deficits are due to a deficient engagement of cortical neuronal networks. It is precisely the notion of deafferentiation of cortical areas that we employ to explain the current findings.

It is noteworthy that in our case study defective scores were found on memory for both visual and verbal stimuli, given the fact that the lateralisation of functions in the brain hemispheres also hold for the thalamus. ${ }^{38}$ One of the rare cases of a right unilateral thalamic infarction reported in the literature is described by Pepin and Auray-Pepin. ${ }^{6}$ In disagreement with our results they showed that in their patient an anterograde amnesia selective for non-verbal material was associated with the right sided infarct. The infarction described by Pepin and Auray-Pepin however, was located differently from that in our study and was far larger, extending into anterior regions of the thalamus to include the mammillothalamic tract. Similarly, Speedie and Heilman reported a patient with a unilateral infarction in the right thalamic area. ${ }^{39}$ The lesion was extensive, affecting the entire mediodorsal nucleus and parts of the anterior complex of nuclei and the pulvinar. They found right sided neuropsychological deficits in terms of memory and frontal processes; visual memory was affected whereas verbal memory remained intact, and design fluency was defective as opposed to verbal fluency. Also, Graff-Radford et al described a patient with an infarction in the territory of the right polar artery, causing a lesion of the anterior part of the right thalamus. ${ }^{40}$ The patient showed decrements of non-verbal memory with good verbal memory. Bogousslavsky et al reported on three patients, of which the third had an infarction located in the anterior right thalamus. ${ }^{41}$ Remarkably, this patient showed deficits in both visual and verbal memory, although the second was relatively less affected. In addition, this patient showed deficient results on tests for executive abilities, the Stroop test and Wisconsin card sorting test.

In 1988, Bogousslavsky et al described a patient with a unilateral right thalamic infarction of the intralaminar, mediodorsal, and ven- 
trolateral nuclei. ${ }^{42}$ This patient showed a marked change in personality, displaying apathy and disinhibited speech. Non-verbal memory seemed affected, but verbal memory was not tested. Of the studies mentioning rightsided infarctions reviewed here, this is the only report in which the lesion overlaps with that described in our patient; however, the lesion is larger and encompasses other structures adjacent to the intralaminar region. Takamatsu et al described a woman with a right sided unilateral infarction in the anteromedial region of the thalamus, initially presenting with verbal and non-verbal anterograde memory deficits. ${ }^{43}$ The initial symptoms cleared however, and the patient showed a residual amnesia for nonverbal material only. By contrast with the reports mentioned above, ${ }^{69-43}$ and similar to our study, Baumgartner and Regard reported three patients with right sided infarctions of the thalamus, two of whom showed evidence of bilateral neuropsychological deficits. ${ }^{44}$ Unfortunately, no pictures or reconstructions of the lesions are presented and it is therefore impossible to judge whether the lesions are similar to the one described in the present paper. A paper by Daum and Ackermann showed a patient with a more anteriorly located right sided infarction. ${ }^{45}$ This patient also displayed defects in verbal and non-verbal memory, in addition to mild signs of frontal dysfunction.

EVIDENCE FOR INVOLVEMENT OF THE INTERNAL MEDULLARY LAMINA RATHER THAN THE DORSOMEDIAL NUCLEUS

It may be argued on the basis of a report by Kritchevsky et al that a small infarction, involving $15 \%$ of the medial part of the right dorsomedial nucleus renders no effects in terms of memory or dysexecutive problems. ${ }^{46}$ This provides additional evidence for the idea that the infarction in our patient cannot be located in the dorsomedial nucleus although involvement of this nucleus might at first sight be suspected because of its proximity to the dorsal internal medullary lamina.

A paper by Shuren et $a l^{47}$ shows the neuropsychological profile of a patient with an infarction similar in size to the one described here. The authors located the lesion in the right thalamus, in the lateral part of the mediodorsal nucleus, just medial to the lesion shown by our patient. Again, the fact that in their patient there was no evidence of slowness, apathy, executive, or attentional disorders, lends further support to the notion that involvement of the mediodorsal nucleus in the patient described in the current paper cannot account for the cognitive profile.

EFFECTS OF THALAMIC STROKE ON CORTICAL PERFUSION

Our patient is unique because of the minute size of his lesion, affecting only part of the right intralaminar complex. The neuropsychological effects of this small diencephalic lesion exemplify the influence of the thalamic intralaminar activating mechanism on cerebral functioning. This is further corroborated by the finding of decreased blood flow in the ipsilateral frontal cortex of this patient. It has been described earlier that lesions in thalamic structures are associated with decreases in regional cerebral blood flow in cortical areas. The distribution of these decreases follows the topography of connectivity between the thalamus and cortical areas; lesions in the medial nucleus of the thalamus are associated with decreased flow in the frontal lobe. ${ }^{6}$ Larger lesions affect regional cerebral blood flow in the entire ipsilateral hemicortex. ${ }^{48}$ It is interesting that Levasseur et al pointed to a crucial role for the "nonspecific" nuclei of the thalamus - that is, the midline and intralaminar nuclei, in diffuse cortical hypometabolism. ${ }^{49}$ The present is to our knowledge the first report of an infarction selectively involving part of the intralaminar complex giving rise to a hypoperfusion of the frontal cortex.

With regard to the bilateral neuropsychological effects of unilateral thalamic stroke it is interesting to note that Baron et al have shown that a unilateral lesion of the thalamus can cause hypoperfusion of the contralateral cortex, albeit slight. ${ }^{50}$ This was studied in patients undergoing electrocoagulation of the nuclei ventrolateralis and ventrointermedius for alleviation of uncontrollable tremor. In our patient, it could obviously not be determined whether the left cortex showed hypoperfusion in addition to the obvious hypoperfusion in the right frontal cortex as only postlesion perfusion data were available.

\section{Concluding remarks}

The present data, although from a single case, illustrate the effects of a small circumscribed area of the thalamus on cognitive functioning. Our data are in accord with those obtained with experimental animals, showing working memory deficits rather than reference memory deficits after selective lesions of the lateral intralaminar nuclei. ${ }^{51-54}$ These working memory deficits were similar to those found after lesions of the frontal cortex, but not to those seen after hippocampal ablation. ${ }^{54}$

The midline and intralaminar nuclei of the thalamus have been shown to receive extensive brainstem innervation, and in turn project to the cerebral cortices in a topographical fashion. ${ }^{55}$ Specifically, the cortical targets of the nuclei in the caudally located part of the internal lamina consist mainly of the prefrontal and parietal cortices. ${ }^{30} 56$ Through concerted action of the various intralaminar nuclei, the thalamus is thought to coordinate the effects of the reticular formation on cerebral functioning. It is thought that the strategically located lesion in the right thalamus described here disconnects the activating brainstem areas from the neocortex. Support for a role of the intralaminar nuclei in attention demanding tasks comes from a report showing increased blood flow in this region when healthy subjects went from a relaxed awake state to a higher degree of activation. ${ }^{57}$ In the current case, the nuclei contained within the internal medullary lamina that subserve the activation of the prefrontal cortical networks are lesioned; the underactivation of the prefrontal cortex leads to the so 
called executive disturbances that are found in the neuropsychological tests. This cognitive underarousal is different from the more specific cognitive disturbances seen after lesioning of the large nuclear masses of the thalamus.

The help of Drs Harry Uijlings, Henk Groenewegen, and Wil Smeets, in determining the location of the lesion is gratefully acknowledged. Thanks are due to two anonymous referees for suggestions concerning both text and content of the manuscript.

1 Zola-Morgan S, Squire LR, Amaral DG. Human amnesia and the medial temporal region: enduring memory impairment following a bilateral lesion limited to field CA1 of the ment following a bilateral lesion limited to

2 Graff-Radford NR, Tranel D, Van Hoesen GW, Brandt JP. Graff-Radford NR, Tranel D, Van Hoesen GW,

3 Von Cramon DY, Hebel N, Schuri U. A contribution to the anatomical basis of thalamic amnesia. Brain 1985;108:9931008 .

4 Sandson TA, Daffner KR, Carvalho PA, et al. Frontal lobe dysfunction following infarction of the left-sided medial thalamus. Arch Neurol 1991;48:1300-3.

5 Bogousslavsky J, Regli F, Uske A. Thalamic infarcts: clinical syndromes, etiology and prognosis. Neurology 1988;38 837-48.

6 Pepin EP, Auray-Pepin L. Selective dorsolateral frontal lobe dysfunction associated with diencephalic amnesia. Neurology 1993;43:733-41.

7 Bogousslavsky J, Regli F, Delaloye B, et al. Loss of psychic self-activation with bithalamic infarction. Acta Neurol Scand 1991;83:309-16.

8 Rousseaux M. Amnesias following limited thalamic infarctions. In: Delacour J, ed. The memory system of the brain. Singapore: World Scientific, 1994:241-277. (Adv Series Neurosci Vol 4.)

9 Peru A, Fabbro F. Thalamic amnesia following venous Peru A, Fabbro F. Thalamic amnesia following venous 1997:33:278-94.

10 Folstein MF, Folstein SE, McHugh PR. Mini-mental state. F Psychiatr Res 1975;12:189-98.

11 Pfeiffer E. SPMSQ: short portable mental status questionnaire. F Am Geriatr Soc 1975;23:433-41.

12 Huber W, Weniger D, Poeck K, et al. The Aachen aphasia test (AAT). In: FC Rose, ed. Progress in aphasiology. New York: Raven, 1984.

13 Van Strien JW. Classification of left-handed and righthanded test subjects. Nederlands Tijdschrift voor de Psychologie en Haar Grensgebieden 1992;47:88-92.

14 Luteijn F. A new abbreviated Groninger intelligencetest (in Dutch). Nederlands Tijdschrift voor de Psychologie en Haar Grensgebieden 1966;21:675-82.

15 Luteijn F, Van der Ploeg FAE. De Groninger Intelligentie Test (The Groningen intelligence test). Lisse, The Netherlands: Swets and Zeitlinger, 1983.

16 Deelman BG, Brouwer WH, Van Zomeren AH, et al. Functional disturbances after head trauma (in Dutch). In: tional disturbances after head trauma (in Dutch). In: Jennekens-Schinkel A, Diamant JJ, Diesfeldt A, et al, eds.
Neuropsychology in the Netherlands. Deventer, The Neuropsychology in the Netherlands.

17 Brand N, Jolles J. Learning and retrieval rate of words presented auditorily and visually. F Gen Psychol 1985;112:20110.

18 Lezak MD. Neuropsychological assessment. 3rd ed. New York: Oxford University Press, 1995

19 Meyers JE, Meyers KR. Rey complex figure test under four different administration procedures. Clinical Neuropsychologist 1995;9:63-7.

20 Lindeboom J. The assessment of anterograde amnesia. $\mathcal{F}$ Clin Exp Neuropsychol 1989;11:345.

21 Rombouts SARB, Machielsen WCM, Witter MP, et al. Visual association encoding shows activation in the medial temporal lobe. A functional magnetic resonance imaging study. Hippocampus 1997;7:594-601.

22 Withdrawn.

23 Warrington EK. Recognition memory test. Windsor, UK: NFER-Nelson, 1984

24 Lindeboom J, Matto D. Digit span and Knox cubes as concentration tests in the elderly (in Dutch). Tijdschr Geronto Geriatr 1994;25:63-8.

25 Stroop JR. Studies of interference in serial verbal reactions. f Exp Psychol 1935;18:643-62.

26 Berg EA. A simple objective treatment for measuring flexibility in thinking. $\mathcal{F}$ Gen Psychol 1948;39:15-22.

27 Shallice T. Specific impairment of planning. Philos Trans $R$ Soc Lond B Biol Med 1982;298:199-209.

28 Van Buren JM, Borke RC. Variations and connections of the human thalamus. New York: Springer-Verlag, 1972.

29 Mai JK, Assheuer J, Paxinos G. Atlas of the human brain. San Diego: Academic Press, 1997:328.
30 Berendse HW, Groenewegen HJ. Restricted cortical termination fields of the midline and intralaminar thalamic nation fields of the midline and intralaminar
nuclei in the rat. Neuroscience 1991;42:73-102.

31 Hirst W, Volpe BT. Automatic and effortful encoding in amnesia. In: Gazzaniga MS, ed. Handbook of neuroscience. New York: Plenum Press, 1984:369-86.

32 Kopelman MD, Stanhope N. Rates of forgetting in organic amnesia following temporal lobe, diencephalic or frontal lobe lesions. Neuropsychology 1997;11:343-56.

33 Scoville WB, Milner B. Loss of recent memory after bilateral hippocampal

34 Squire LR, Amaral DG, Zola-Morgan S, et al. Description of brain injury in the amnesic patient NA based on of brain injury in the amnesic patient NA based on

35 Zola-Morgan S, Squire LR. Neuroanatomy of memory. Aппи Rev Neurosci 1993;16:547-63.

36 Mennemeier M, Fennell E, Valenstein E, et al. Contributions of the left intralaminar and medial thalamic nuclei to memory. Comparisons and report of a case. Arch Neurol 1992;49:1050-8.

37 Mennemeier M, Crosson B, Williamson DJ, et al. Tapping talking and the thalamus: possible influence of the intralaminar nuclei on basa ganglia function. Neuropsychologia 1997;35:183-93.

38 Ojemann GA. Asymmetric functions of the thalamus in man. Ann NY Acad Sci 1977;299:380-96.

39 Speedie LJ, Heilman KM. Anterograde memory deficits for visuospatial material after infarction of the right thalamus. Arch Neurol 1983;40:183-6.

40 Graff-Radford NR, Eslinger PJ, Damasio AR, et al. Non-hemorrhagic infarction of the thalamus: behavioral, anatomic, and physiologic correlates. Neurology 1984;34: $14-23$.

41 Bogousslavsky J, Regli F, Assal G. The syndrome of unilateral tuberothalamic artery territory infarction. Stroke 1986; 17:434-41.

42 Bogousslavsky J, Ferrazzini M, Regli F, et al. Manic delirium and frontal-like syndrome with paramedian infarction of the right thalamus. $\mathcal{F}$ Neurol Neurosurg Psychiatry 1988a;51: $116-9$.

43 Takamatsu K, Yamamoto M, Yamano T, et al. A case of amnestic syndrome due to right thalamic infarction. Fapanese Medical fournal 1990;29:301-4.

44 Baumgartner RW, Regard M. Bilateral neuropsychological deficits in unilateral paramedian thalamic infarction. Eur Neurol 1993;33:195-8.

45 Daum I, Ackermann H. Frontal-type memory impairment associated with thalamic damage. Int $\mathcal{F}$ Neurosci 1994;77: $187-98$.

46 Kritchevsky M, Graff-Radford NR, Damasio AR. Normal memory after damage to medial thalamus. Arch Neurol 1987;44:959-62.

47 Shuren JE, Jacobs DH, Heilman KM. Diencephallic temporal order amnesia. F Neurol Neurosurg Psychiatry 1997;62: 63-8.

48 Baron JC, D'Antona R, Pantano P, et al. Effects of thalamic stroke on energy metabolism of the cerebral cortex. A positron tomography study in man. Brain 1986;109:1243-59.

49 Levasseur M, Baron JC, Sette G, et al. Brain energy metabolism in bilateral paramedian thalamic infarcts. A positron emission tomography study. Brain 1992;115:795-807.

50 Baron JC, Levasseur M, Mazoyer B, et al. Thalamocortical diaschisis: positron emission tomography in humans. $\mathcal{f}$ Neurol Neurosurg Psychiatry 1992;55:935-42.

51 Koger SM, Mair RG. Comparison of the effects of frontal cortical and thalamic lesions on measures of olfactory learning and memory in the rat. Behav Neurosci 1994;108. $1088-100$.

52 Mair RG, Lacourse DM. Radiofrequency lesions of the thalamus produce delayed-nonmatching-to-sample impairments comparable to pyrithiamine-induced encephalopathy in rats. Behav Neurosci 1992;106:634-45.

53 Savage LM, Sweet AJ, Castillo R, et al. The effects of lesions to thalamic lateral internal medullary lamina and posterior nuclei on learning, memory and habituation in the rat. Behav Brain Res 1997;82:133-47.

54 Young HL, Stevens AA, Converse E, et al. A comparison of temporal decay in place memory tasks in rats (Rattus norvegicus) with lesions affecting thalamus, frontal cortex, or the hippocampal system. Behav Neurosci 1996;110:124460.

55 Groenewegen HJ, Berendse HW. The specificity of the "nonspecific" midline and intralaminar thalamic nuclei. Trends Neurosci 1994;17:52-7.

56 Royce GJ, Mourey RJ. Efferent connections of the centromedian and parafascicular thalamic nuclei: an autoradiographic investigation in the cat. I Comp Neurol 1985;235:277-300.

57 Kinomura S, Larsson J, Gulyas B, et al. Activation of the human reticular formation and thalamic intralaminar nuclei. Science 1996;271:512-5. 